\title{
GERMINAÇÃO DE SEMENTES DE COUVE CHINESA SOB INFLUÊNCIA DO TEOR DE ÁGUA, SUBSTRATO E ESTRESSE SALINO ${ }^{1}$
}

\author{
JOSÉ CARLOS LOPES; CÉLIA MARIA PEIXOTO DE MACEDO³
}

\begin{abstract}
RESUMO - Este trabalho teve como objetivo avaliar a germinação e o vigor de sementes de couve chinesa (Brassica pekinensis) cv. Granat, sob a influência do teor de água, substrato e estresse salino. A pesquisa foi conduzida no Laboratório de Análise de Sementes do Departamento de Fitotecnia do Centro de Ciências Agrárias da Universidade Federal do Espírito Santo, CCA-UFES, em AlegreES, em delineamento inteiramente casualizado, com os tratamentos distribuídos em esquema fatorial $2 \times 3 \times 5$. Utilizaram-se dois lotes de sementes com teores de água ajustados para $8 \%$ e $16 \%$ (base úmida), colocados para germinar sobre areia, sobre papel ou entre papel, sendo os substratos umedecidos com solução salina $(\mathrm{NaCl})$ nas concentrações de zero, $-0,2 ;-0,4 ;-0,6$ e $-0,8 \mathrm{MPa}$. As sementes foram mantidas em germinador a temperatura de $20-30^{\circ} \mathrm{C}$. As características avaliadas foram: porcentagem de germinação (\%), índice de velocidade de germinação (IVG), massa fresca e massa seca das plântulas. Porcentagem e velocidade de germinação mais elevadasforam observadas nas sementes mantidas com grau de umidade inicial de $8 \%$, semeadura sobre papel. A germinação e o vigor foram afetados pela salinidade. Sementes com grau de umidade inicial de $16 \%$, sob as concentrações salinas de $-0,2$ e $-0,4 \mathrm{MPa}$, nas semeaduras entre papel e sobre areia originaram plântulas com maior acúmulo de massa fresca, enquanto o maior acúmulo de massa seca foi obtido sob a concentração de $-0,8 \mathrm{MPa}$. Assim, a salinidade afeta a manifestação do potencial fisiológico das sementes de Brassica pekinensis, sendo os prejuízos proporcionais à redução do potencial osmótico. As observações efetuadas demonstram que a couve chinesa apresenta maior tolerância à salinidade na fase de desenvolvimento inicial das plantas.
\end{abstract}

Termos para indexação: Brassica pekinensis, potencial osmótico, vigor.

\section{GERMINATION OF BRASSICA PEKINENSIS AFFECTED BY SEED MOISTURE CONTENT, SUBSTRATE AND SALINE STRESS}

\begin{abstract}
This work evaluated seed germination and vigor of Brassica pekinensis cv. granat as affected by moisture content, substrate and saline stress. The experiment was carried out at the Seed Laboratory of the Agrarian Center Science of Universidade Federal do Espirito Santo, in AlegreES, in a completely randomized design with the treatments distributed in a $2 \times 3 \times 5$ factorial scheme to test the influence of seed moisture content ( 8 and 16\%), substrate (top of sand, top of paper and between paper) and four $\mathrm{NaCl}$ solution concentrations (-0.2; -0.4 ; - 0.6 e $-0.8 \mathrm{MPa})$. Germination test was performed at $20-30^{\circ} \mathrm{C}$. The following parameters were considered: percentage and speed of germination, seedling fresh and dry weight. Percentage and speed of germination in a top of paper sowing was higher for the $8 \%$ M.C. seed lot. Seed germination and vigor decreased as salt concentrations increased. The seeds of $16 \%$ M.C. sown at top of sand and between paper, with salt
\end{abstract}

${ }^{1}$ Submetido em 11/04/2008. Aceito para publicação em 21/07/2008.

${ }^{2}$ Engenheiro Agrônomo, Doutor em Fisiologia Vegetal, Professor Associado I, Dept ${ }^{\circ}$ de Produção Vegetal, Centro de Ciências Agrárias da Universidade Federal do Espírito Santo (CCA-UFES), Cx. Postal 16, 29500-000,
Alegre (ES) - jcufes@bol.com.br;

${ }^{3}$ Engenheira Agrônoma, Mestre em Produção Vegetal - Rua Monteiro da Gama, 29500-000, Alegre (ES), celiampm@yahoo.com.br. 
solution of -0.2 and -0.4 MPa showed increases in seedling fresh weight, while significant increase of dry weight was observed at $-0.8 \mathrm{MPa}$. In conclusion, salinity is deleterious to Brassica pekinensis seed performance and damages are proportional to decrease of the osmotical potential. Seeds showed to be more tolerant to water deficit durning the initial stages of plant development.

Index terms: Brassica pekinensis, osmotic potential, vigor, salt stress

\section{INTRODUÇÃO}

A utilização da couve-chinesa (Brassica pekinensis) na alimentação humana vem se destacando, com consumo aproximado de $500 \mathrm{~g}$ pessoa $^{-1} \mathrm{dia}^{-1}$. Essa hortaliça, da família das brassicaceas, também é conhecida como repolho chinês, provavelmente originária da China. Apresenta folhas enrugadas, de cor verde claro e superpostas, formando cabeça de formato alongado (Filgueira, 2000).

Nos últimos anos, a produção de sementes de hortaliças, no Brasil, teve uma demanda crescente por mateirais de melhor qualidade, em conseqüência do aprimoramento dos sistemas de produção comercial. Apesar dos avanços, muito ainda há por fazer, não só para alcançar a auto-suficiência em relação à produção, mas também em relação à obtenção de sementes de qualidade superior. A alta qualidade de sementes se reveste de grande importância, principalmente quanto à necessidade de garantir um estande ideal de plantas. Neste contexto, a semente de alto vigor constitui elemento básico e fundamental.

A germinação é caracterizada pela protrusão da raiz primária, que apenas se completa quando o teor de água da semente exceder um valor crítico que possibilite a ativação dos processos metabólicos promotores do crescimento do eixo embrionário (Tambelini e Perez, 1998). O sucesso no processo germinativo é dependente do movimento de água através dos tecidos que envolvem a semente. A presença de sais interfere no potencial hídrico do solo, reduzindo o gradiente de potencial entre o solo e a superfície da semente, restringindo a captação de água pela semente. As condições encontradas pelas sementes nem sempre são ideais, como é o caso dos solos salinos, devido à fertilização dos solos e à fertirrigação associadas à deficiência de sistema adequado para a drenagem. Nesses solos, a presença de sais pode atingir nível elevado e influenciar significativamente a germinação. Quando o potencial osmótico da solução é inferior (mais negativo) ao das células do embrião, ocorre a redução da velocidade e/ou porcentagem de germinação e da formação de plântulas (Harding et al., 1958; Santos et al., 1992; Carvalho e Nakagawa, 2000). Essa ocorrência foi relatada para sementes de várias espécies, como soja (Santos et al.,
1992), pepino (Torres et al., 2000), Adenanthera pavoniana (Fonseca e Perez, 2001), cenoura (Lopes e Dias, 2004). A salinização dos solos afeta negativamente a germinação, o estande inicial, o desenvolvimento vegetativo das culturas, a produtividade e, nos casos mais graves, causa a morte das plântulas (Silva e Pruski, 1997), não só pela dificuldade de absorção de água pelas sementes como também por facilitar a entrada de íons em concentração tóxica (Bliss et al., 1986; Ferreira e Rebouças, 1992; Ferreira, 1997). Alto teor de sais no solo, principalmente $\mathrm{NaCl}$, pode inibir a germinação, devido aos efeitos osmótico e tóxico (Bliss et al., 1986). No caso da semeadura em substratos artificiais, sua escolha deve ser feita levando em consideração a constituição física, química e biológica, que podem afetar o processo germinativo (Barbosa et al., 1985), principalmente quando os substratos apresentam sais de alta solubilidade em sua constituição química, para que a germinação não seja severamente prejudicada (Ferreira, 1997).

Este trabalho teve como objetivo avaliar a germinação e o vigor de sementes de couve chinesa (Brassica pekinensis cv. Granat) sob a influência dos diferentes teores de água, substrato e estresse salino.

\section{MATERIAL E MÉTODOS}

O trabalho foi conduzido no Laboratório de Tecnologia e Análise de Sementes do Centro de Ciências Agrárias da Universidade Federal do Espírito Santo, Alegre-ES. Foram utilizadas sementes de couve chinesa (Brassica pekinensis) cv. Granat, adquiridas no comércio local. As sementes foram divididas em dois lotes, um com o teor de água de $8 \%$ e o outro com 16\% (ambos na base úmida), obtidos pela manutenção dos lotes em câmara úmida e monitorados com avaliações periódicas. $\mathrm{O}$ experimento foi conduzido com quatro repetições de 25 sementes, em placas de Petri; os substratos utilizados foram areia (semeadura sobre areia - SA) e papel (semeaduras sobre - SP- e entre papel - EP), umedecidos com quantidade de solução de $\mathrm{NaCl}$ equivalente a 2,5 vezes o peso do substrato, nas concentrações de zero (controle), $-0,2 ;-0,4 ;-0,6$ e $-0,8 \mathrm{MPa}$. Os testes foram conduzidos sob alternância $20-30^{\circ} \mathrm{C}$. 
As avaliações foram realizadas aos cinco e aos sete dias após a semeadura (Brasil, 1992). Para avaliação do vigor, feita pelo cálculo da velocidade de germinação (Maguire, 1962), foram consideradas germinadas as sementes que apresentaram raiz primária com, no mínimo, dois milímetros de comprimento. Após 10 dias, as plântulas normais de cada repetição em todos os tratamentos foram identificadas, os cotilédones removidos com auxílio de um bisturi e determinada a massa fresca, em seguida, esse material vegetal foi colocado em estufa a $80 \pm 2^{\circ} \mathrm{C}$ até a obtenção de massa constante (três dias) e determinada a massa seca. Os valores totais da massa fresca e da seca foram divididos pelo número de plântulas avaliadas em cada repetição e, os resultados, expressos em mg plântula ${ }^{-1}$ para cada lote.

O delineamento experimental utilizado foi o inteiramente casualizado, com quatro repetições, em esquema fatorial de
$2 \times 3 \times 5$ (teores de água, substratos e potenciais osmóticos). Os dados obtidos em porcentagem foram transformados em arc sem $\sqrt{ } \mathrm{x} / 100$. Para comparação entre as médias foi utilizado o teste de Tukey, $(\mathrm{p} \leq 0,05)$.

\section{RESULTADOS E DISCUSSÃO}

O teor de água das sementes antes da instalação do teste apresentou variações de 0,2 a 0,4 pontos percentuais $(8,0 \pm 0,2 \%$ e $16 \pm 0,4 \%)$; de acordo com Marcos Filho (2005) essa uniformização é importante para obtenção de resultados consistentes durante as avaliações.

Dentre as interações estudadas, ou seja, potencial osmótico x substrato, potencial osmótico $\mathrm{x}$ teor de água $\mathrm{e}$ substrato $\mathrm{x}$ teor de água, somente a última foi significativa para a porcentagem de germinação (Tabela 1).

TABELA 1. Germinação (\%), índice de velocidade de germinação (IVG), massa fresca e seca (mg) de sementes de cv. granat em diferentes teores de água e substratos. CCA-UFES, Alegre-ES, 2008.

\begin{tabular}{|c|c|c|c|c|c|c|}
\hline \multirow{3}{*}{ Substratos } & \multicolumn{3}{|c|}{ Germinação (\%) } & \multicolumn{3}{|c|}{ IVG } \\
\hline & \multicolumn{3}{|c|}{ Teor de água (\%) } & \multicolumn{3}{|c|}{ Teor de água (\%) } \\
\hline & 8 & & 16 & $\varepsilon$ & & 16 \\
\hline Sobre areia & $73 \mathrm{Ba}$ & & $77 \mathrm{Aa}$ & 5,98 & & $6,50 \mathrm{Aa}$ \\
\hline Sobre papel & $86 \mathrm{Aa}$ & & $73 \mathrm{Ab}$ & 6,83 & & $5,86 \mathrm{Ab}$ \\
\hline \multirow[t]{4}{*}{ Entre papel } & $78 \mathrm{ABa}$ & & $68 \mathrm{Ab}$ & 6,65 & & $5,40 \mathrm{Ab}$ \\
\hline & \multicolumn{2}{|c|}{ Massa Fresca } & \multirow{3}{*}{ Média } & \multicolumn{2}{|c|}{ Massa Seca } & \\
\hline & \multicolumn{2}{|c|}{ Teor de água (\%) } & & \multicolumn{2}{|c|}{ Teor de água (\%) } & Média \\
\hline & 8 & 16 & & 8 & 16 & \\
\hline Sobre areia & 50,02 & 57,69 & 53,86 a & 1,98 & 2,01 & $1,93 \mathrm{a}$ \\
\hline Sobre papel & 34,85 & 37,92 & $36,39 \mathrm{~b}$ & 1,80 & 2,06 & $1,92 \mathrm{a}$ \\
\hline Entre papel & 47,90 & 47,90 & $48,72 \mathrm{a}$ & 1,91 & 1,92 & $2,00 \mathrm{a}$ \\
\hline Média & $44,25 \mathrm{~B}$ & $48,39 \mathrm{~A}$ & & $1,90 \mathrm{~A}$ & $2,00 \mathrm{~A}$ & \\
\hline
\end{tabular}

${ }^{1}$ Médias seguidas pela mesma letra, maiúscula na coluna e minúscula na linha, não diferem entre si pelo teste de Tukey, à 5\% de probabilidade.

A máxima capacidade germinativa em presença da solução osmótica foi verificada no tratamento $-0,2 \mathrm{MPa}$, não diferindo do controle. Houve decréscimo da porcentagem de germinação sob influência do potencial osmótico de $-0,8$ MPa (Tabela 2). O aumento da concentração de sais no substrato determina redução no potencial hídrico, resultando em menor capacidade de absorção de água pelas sementes, o que geralmente influência a capacidade germinativa e no desenvolvimento das plântulas (Rebouças et al., 1989). A presença de níveis mais elevados de íons em plantas não halófitas (menos tolerantes à deficiência hídrica), pode exercer efeitos adversos na permeabilidade das membranas celulares (Greenway e Munns, 1980); isto possivelmente contribuiu para a redução da germinação sob a influência do potencial osmótico de -0,8 MPa. Em trabalhos com beterraba, Marschner (1995) verificou que essa espécie é sensível à disponibilidade de água durante a germinação. Em contraste, a sensibilidade aumenta durante o desenvolvimento das plantas, em arroz, tomate, trigo e cevada, após a germinação (Maas e Hoffmann, 1977), de modo que há variações da germinação de desenvolvimento das plantas de diferentes espécies sob estresse salino. Frett et al. (1991) afirmaram 
que a absorção de íons da solução salina pelas sementes pode determinar distúrbio no balanço osmótico das células, estimulando o influxo de água nas sementes, bem como causar toxidez às plântulas. Por outro lado, esse comportamento pode ser influenciado pela disponibilidade hídrica em função do tipo de substrato e potencial da água no mesmo. Torres et al. (2000) avaliando os efeito da salinidade na germinação e no desenvolvimento de plântulas de pepino, verificaram que a redução progressiva do potencial osmótico de $\mathrm{NaCl}$ do substrato foi prejudicial à germinação e ao desenvolvimento das plântulas a partir de potenciais osmóticos inferiores a -0,4 MPa. Duarte et al. (2006) e Torres (2007) verificaram que a redução do potencial osmótico de $\mathrm{NaCl}$ do substrato é prejudicial à germinação e ao desenvolvimento de plântulas de trigo e melancia, respectivamente.

TABELA 2. Germinação (\%) de sementes, índice de velocidade de germinação (IVG), massa fresca e massa seca (mg) de plântulas de Brassica pekinensis cv. Granat submetidas a diferentes potenciais osmóticos e substratos. CCA-UFES, Alegre-ES, 2008.

\begin{tabular}{|c|c|c|c|c|c|c|}
\hline \multirow{2}{*}{ Substratos } & \multicolumn{5}{|c|}{ Potencial osmótico do meio germinativo com $\mathrm{NaCl}(\mathrm{MPa})$} & \multirow[b]{2}{*}{ Média } \\
\hline & 0 & $-0,2$ & $-0,4$ & $-0,6$ & $-0,8$ & \\
\hline \multicolumn{7}{|c|}{ Germinação } \\
\hline S. Areia & 71 & 78 & 81 & 72 & 69 & $74 \mathrm{AB}$ \\
\hline S. Papel & 89 & 84 & 80 & 79 & 62 & $79 \mathrm{~A}$ \\
\hline E. Papel & 79 & 79 & 75 & 74 & 59 & $73 \mathrm{~B}$ \\
\hline Média & $80 \mathrm{a}$ & $80 \mathrm{a}$ & $79 \mathrm{a}$ & $75 \mathrm{a}$ & $64 b$ & \\
\hline \multicolumn{7}{|c|}{ Índice de velocidade de germinação } \\
\hline S. Areia & $6,24 \mathrm{Bab}$ & 7,00 Aa & $6,78 \mathrm{Aa}$ & $6,20 \mathrm{Aab}$ & $4,97 \mathrm{Ab}$ & \\
\hline S. Papel & $8,52 \mathrm{Aa}$ & 7,78 Aab & 6,36 Aab & $5,42 \mathrm{Ac}$ & $3,65 \mathrm{Ad}$ & \\
\hline E. Papel & $7,11 \mathrm{Ba}$ & 7,43 Aa & 6,36 Aab & $5,38 \mathrm{Abc}$ & $3,86 \mathrm{Ac}$ & \\
\hline \multicolumn{7}{|c|}{ Massa Fresca } \\
\hline S. Areia & $52,09 \mathrm{Aab}$ & $64,69 \mathrm{Aa}$ & $57,74 \mathrm{Aa}$ & $51,44 \mathrm{Aab}$ & $43,34 \mathrm{Abb}$ & \\
\hline S. Papel & $36,34 \mathrm{Ba}$ & $32,27 \mathrm{Ba}$ & $40,56 \mathrm{Ba}$ & $41,40 \mathrm{Aa}$ & $31,36 \mathrm{Ba}$ & \\
\hline E. Papel & $39,96 \mathrm{ABb}$ & $55,99 \mathrm{Aa}$ & $55,60 \mathrm{Aa}$ & $45,07 \mathrm{Aab}$ & 46,97 Aab & \\
\hline \multicolumn{7}{|c|}{ Massa Seca } \\
\hline S. Areia & $2,07 \mathrm{Aa}$ & 2,07 Aa & $2,09 \mathrm{Aa}$ & $2,00 \mathrm{Aa}$ & $1,75 \mathrm{Ba}$ & \\
\hline S. Papel & $1,75 \mathrm{ABb}$ & $1,69 \mathrm{Ab}$ & $1,86 \mathrm{Ab}$ & $2,00 \mathrm{Ab}$ & $2,37 \mathrm{Aa}$ & \\
\hline E. Papel & $1,49 \mathrm{Bc}$ & $1,77 \mathrm{~A} \mathrm{bc}$ & 1,99 Aab & 2,04 Aab & $2,30 \mathrm{Aa}$ & \\
\hline
\end{tabular}

${ }^{1}$ Médias seguidas pela mesma letra, maiúscula na coluna e minúscula na linha, não diferem entre si pelo teste de Tukey, a 5\% de probabilidade.

A germinação variou significativamente de acordo com os teores iniciais de água da semente, à exceção da semeadura sobre areia, em sementes com grau de umidade de $8 \%$ (Tabelas 1 e 3). Os valores de germinação não diferiram estatisticamente entre os substratos, sob influência do teor de água de $16 \%$ (Tabelas 1 e 2). A velocidade de absorção de água pela semente varia com a espécie, permeabilidade das membranas, concentração de água, temperatura, pressão hidrostática, área de contato da semente com a água e forças intermoleculares (Popinigis, 1985). Por serem higroscópicas, as sementes cedem ou captam água do substrato com maior ou menor velocidade, de modo que o processo de embebição é dependente do gradiente hídrico entre a semente e o meio externo. A redução da germinação das sementes submetida ao estresse hídrico é atribuída à redução da atividade enzimática, a qual promove menor desenvolvimento meristemático 
(Santos et al., 1992).

$\mathrm{Na}$ avaliação do vigor das sementes, pelo índice de velocidade de germinação, a interação potencial osmótico $\mathrm{x}$ substrato e substrato $\mathrm{x}$ teor de água foram significativas, enquanto a interação potencial osmótico $\mathrm{x}$ teor de água não foi significativa. Entretanto, na semeadura entre papel, houve diferença entre os comportamentos dos lotes em função dos teores iniciais de água (Tabela 1). Tanto na percentagem como na velocidade de germinação, os maiores valores obtidos corresponderam às sementes com teor de água inicial de $8 \%$ (Tabela 3). Na interação substrato $\mathrm{x}$ teor de água não se verificou diferença significativa entre os sistemas de semeadura (Tabela 1); porém, na interação potencial osmótico x substrato, somente o controle $(0,0$ $\mathrm{MPa}$ ) apresentou diferença entre os substratos, com destaque para a germinação sobre papel, que proporcionou maior valor do IVG (Tabela 2). Em relação ao potencial osmótico, os maiores índices de velocidade de germinação foram observados nas concentrações de $0,0 \mathrm{MPa}$ e -0,2 MPa (Tabelas 2 e 3). Apesar do índice de velocidade de germinação ser considerado proporcional ao vigor da semente, a queda no IVG com o aumento na concentração de $\mathrm{NaCl}$ indica que as sementes de couve chinesa sensívies à salinilidade durante a germinação. Esta afeta a germinação dificultando a cinética de absorção de água e facilitando a entrada de íons em quantidade tóxica às sementes durante a embebição (Santos et al., 1992). A germinação e o crescimento inicial de plântulas são considerados os estádios de desenvolvimento mais sensíveis à salinidade e independem da tolerância da planta mãe ao sal (Mayer e Poljakoff-Mayber, 1989). O aumento do teor de sais no substrato determina redução do potencial hídrico, resultando em menor capacidade de absorção de água pelas sementes, influenciando diretamente a germinação e o desenvolvimento das plantas (Rebouças, et al., 1989), por exercer ação tóxica sobre o embrião (Fonseca e Peres, 1999).

TABELA 3. Germinação (\%) de sementes, índice de velocidade de germinação (IVG), massa fresca e massa seca (mg) de plântulas de Brassica pekinensis cv. Granat submetidas a diferentes potenciais osmóticos e teor de água. CCA-UFES, Alegre-ES, 2008.

\begin{tabular}{|c|c|c|c|c|c|c|}
\hline \multirow{3}{*}{ Umidade } & \multicolumn{5}{|c|}{ Potencial osmótico do meio germinativo com $\mathrm{NaCl}(\mathrm{MPa})$} & \multirow[b]{2}{*}{ Média } \\
\hline & 0 & $-0,2$ & $-0,4$ & $-0,6$ & $-0,8$ & \\
\hline & \multicolumn{5}{|c|}{ Germinação } & \\
\hline 8 & 84 & 86 & 77 & 79 & 70 & $79 \mathrm{~A}$ \\
\hline 16 & 76 & 75 & 81 & 72 & 57 & $72 \mathrm{~B}$ \\
\hline Média & $80 \mathrm{a}$ & $80 \mathrm{a}$ & $79 \mathrm{a}$ & $75 \mathrm{a}$ & $64 \mathrm{~b}$ & \\
\hline \multicolumn{7}{|c|}{ Índice de velocidade de germinação } \\
\hline 8 & 7,62 & 8,02 & 6,31 & 5,98 & 4,50 & $6,49 \mathrm{~A}$ \\
\hline 16 & 6,97 & 6,78 & 6,68 & 5,35 & 3,82 & $5,92 \mathrm{~B}$ \\
\hline Média & $7,29 \mathrm{a}$ & $7,40 \mathrm{a}$ & $6,50 a b$ & $5,67 \mathrm{~b}$ & $4,16 \mathrm{c}$ & \\
\hline \multicolumn{7}{|c|}{ Massa Fresca } \\
\hline 8 & 37,40 & 47,03 & 50,04 & 44,30 & 42,48 & $44,25 \mathrm{~B}$ \\
\hline 16 & 48,19 & 54,94 & 52,56 & 47,64 & 38,63 & $48,39 \mathrm{~A}$ \\
\hline Média & $42,80 \mathrm{ab}$ & $50,98 \mathrm{a}$ & $51,30 \mathrm{a}$ & $45,97 \mathrm{ab}$ & $40,56 \mathrm{~b}$ & \\
\hline \multicolumn{7}{|c|}{ Massa seca } \\
\hline 8 & $1,52 \mathrm{Bc}$ & $1,75 \mathrm{Abc}$ & $2,02 \mathrm{Aab}$ & $1,98 \mathrm{Aab}$ & $2,22 \mathrm{Aa}$ & \\
\hline 16 & $2,02 \mathrm{Aa}$ & 1,94 Aa & 1,94 Aa & 2,04 Aa & $2,06 \mathrm{Aa}$ & \\
\hline
\end{tabular}

${ }^{1}$ Médias seguidas pela mesma letra, maiúscula na coluna e minúscula na linha, não diferem entre si pelo teste de Tukey, a 5\% de probabilidade.

Para a massa fresca da parte aérea, somente a interação potencial osmótico $\mathrm{x}$ substrato foi significativa (Tabela 2), sugerindo que as plântulas desenvolvidas a partir das semeaduras sobre areia e entre papel apresentaram maior conteúdo de massa fresca, sem, contudo, diferirem entre si.
Considerando-se as médias obtidas para os três substratos, verificou-se maior acúmulo de massa fresca quando se avaliaram as concentrações de $-0,2 \mathrm{MPa}$ e $-0,4 \mathrm{MPa}$ (Tabelas 2 e 3); ao mesmo tempo, maiores valores de massa fresca foram obtidos em plântulas oriundas das sementes com $16 \%$ 
de água (Tabela 1), evidenciando que o maior teor inicial de água nas sementes restringe, em parte, a absorção de $\mathrm{NaCl}$, em função de um ajustamento osmótico. Provavelmente, devido à sensibilidade das sementes aos efeitos da salinidade, quando em contato com soluções salinas, há redução inicial na absorção de água (Ferreira e Rebouças, 1992).

Quanto às análises realizadas para a massa seca, somente a interação dos fatores substrato e teor de água não foi significativa. O potencial osmótico não interferiu na produção de massa seca das plântulas oriundas de sementes com teor de água de 16\% (Tabela 3); porém, para o teor de água de 8\%, observou-se que na concentração - $0,8 \mathrm{MPa}$ houve aumento no conteúdo de massa seca (Tabela 2), sugerindo que a couve chinesa pode apresentar maior tolerância à salinidade na fase de desenvolvimento inicial das plantas. Em relação às médias referentes aos efeitos dos substratos, não houve diferença significativa (Tabela 1), mas na interação potencial osmótico x substrato, foi observado que na concentração de 0,0 MPa o resultado mais favorável foi obtido na semeadura sobre areia e, na concentração $-0,8 \mathrm{MPa}$, entre papel (Tabela 2). A velocidade de hidratação das sementes está diretamente associada à disponibilidade hídrica, potencial mátrico do substrato, potencial osmótico da solução que umedece o substrato, temperatura e características intrínsecas da semente (Vertucci e Leopold, 1983; Popinigis, 1985). A solução salina determina redução inicial na absorção de água pela semente (Ferreira e Rebouças, 1992), sendo que a sensibilidade a maiores ou menores concentrações de sais no solo é característica de cada tipo de planta e os efeitos no rendimento da cultura poderão ser influenciados por outros fatores como natureza osmótica, tóxica ou nutricional (Viana, et al., 2004).

\section{CONCLUSÕES}

A salinidade afeta a manifestação do potencial fisiológico pela germinação e o vigor das sementes de Brassica pekinensis, sendo os prejuízos proporcionais à redução do potencial osmótico. A couve chinesa apresenta maior tolerância à salinidade na fase de desenvolvimento inicial das plantas.

\section{REFERÊNCIAS}

BARBOSA, J.M.F.; BARBOSA, L.M.M.; PINTO, M.M. Influência do substrato, da temperatura e do armazenamento, sobre a germinação de sementes de quatro espécies nativas. Revista Brasileira de Sementes, v.10, n.1, p.46-54, 1985.
BLISS, R.D.; PLATT-ALOIA, K.A.;THOMPSON, W.W. Plant cell environment. [S.1.:s.n.], 1986. 727p.

BRASIL, Ministério da Agricultura e Reforma Agrária. Regras para análise de sementes. Brasília, DF: SNDA/ DNDV/CLAV, 1992. 365p.

CARVALHO, N.M.; NAKAGAWA, J. Sementes: ciência, tecnologia e produção. 4.ed. Jaboticabal: FUNEP, 2000. 588 p.

DUARTE, G.L.; LOPES, N.F.; MORAES, D.M.; SILVA, R.N. Physiological quality of wheat seeds submitted to saline stress. Revista Brasileira de Sementes, v.28, n.1, p.122-126, 2006.

FERREIRA, P.A. Aspectos físico-químicos do solo. In: GHEVY, H.R.; QUEIROZ, J.E.; MEDEIROS, J.F. Manejo e controle da salinidade na agricultura irrigada. Campina Grande: UFPB/SBEA, 1997. p.37-67.

FERREIRA, L.G.R.; REBOUÇAS, M.A.A. Influência da hidratação/desidratação de sementes de algodão na superação dos efeitos da salinidade na germinação. Pesquisa Agropecuária Brasileira, v.27, n.4, p.609-615, 1992.

FILGUEIRA, F.A.R. Novo manual de olericultura: agrotecnologia moderna na produção e comercialização de hortaliças. 2.ed. Viçosa: Universidade Federal de Viçosa, 2000. 412p.

FONSECA, S.L.C.; PEREZ, C.J.G.A. Germinação de sementes de olho-de-dragão (Adenanthera pavoniana L.): ação de poliaminas na atenuação do estresse salino. Revista Brasileira de Sementes, v.23, n.2, p.14-20, 2001.

FRETT, J.J.; PILL, W.G.; MORNEAU, D.C. A comparison of priming agents for tomato and asparagus seeds. HortScience, v.26, n.9, p.1158-1159, 1991.

GREENWAY, H.; MUNNS, R. Mechanisms of salt tolerance in nonhalophytes. Annual Review of Plant Physiology, v.31, p.149-190, 1980.

HARDING, R.B.; PRATT, P.F.; JONES, N.W. Changes in salinity nitrogen, and soil reaction in a differentially fertilized soil. Soil Science, v.85, n.1, p.117-185, 1958.

LOPES, J.C.; DIAS, M.A. Efeito do estresse salino no vigor e na germinação de sementes e desenvolvimento inicial de plântulas de cenoura. Horticultura Brasileira, v.22, n.2, 2004. CONGRESSO BRASILEIRO DE OLERICULTURA, 44., 2004, Campo Grande.

MAAS, E.V.; HOFFMAN, G.J. Crop salt tolerance: current assessment. Journal of Irrigation and Drainage Division, v.103, n. IR 2, p.115-134, 1977. 
MAGUIRE, J.D. Speed of germination-aid in selection and evaluation for seedling emergence and vigor. Crop Science, v.2, n.2, p.176-177, 1962.

MARCOS FILHO, J. Fisiologia de sementes de plantas cultivadas. Piracicaba: Fealq, 2005. 495p.

MARSCHNER, H. Mineral nutrition of higher plants. 2.ed. San Diego: Academic Press, 1995. 889p.

MAYER, A.M.; POLJAKOFF-MAYBER, A. The germination of seeds. 4.ed. Great Britain: Pergamon Press, 1989. 270p.

POPINIGIS, F. Fisiologia da semente. Brasília: AGIPLAN, 1985. 289p.

REBOUÇAS, M.A.; FAÇANHA, J.G.V.; FERREIRA, L.G.R.; PRISCO, J.T. Crescimento e conteúdo de N, P, K e $\mathrm{Na}$ em três cultivares de algodão sob condições de estresse salino. Revista Brasileira de Fisiologia Vegetal, v.1, n.1, p.79-85, 1989.

SANTOS,V.L.M.;CALIL,A.C.,RUIZ,H.A.;ALVARENGA, E. M.; SANTOS, C. M. Efeito do estresse salino e hídrico na germinação e vigor de sementes de soja. Revista Brasileira de Sementes, v.14, n.2, p.189-194, 1992.

SILVA， D.; PRUSKI， F.F. Recursos hídricos e desenvolvimento sustentável da agricultura. Brasília: MMA, SBH, ABEAS, 1997. 252p.

TAMBELINE, M.; PEREZ, S.C.J.G. Efeito do estresse hídrico simulado com PEG (6000) ou manitol na germinação de sementes de barbatimão (Stryphnodendron polyphyllum Mart.). Revista Brasileira de Sementes, v.20, n.1, p.226232, 1998.

TORRES, S.B. Germinação e desenvolvimento de plântulas de melancia em função da salinidade. Revista Brasileira de Sementes, v.29, n.3, p.68-72, 2007.

TORRES, S.B.; VIEIRA, E.L.; MARCOS-FILHO, J. Salinidade na germinação e no desenvolvimento de plântulas de pepino. Revista Brasileira de Sementes, v.22, n.2, p.3944, 2000.

VERTUCCI, C.W.; LEOPOLD, A.C. Dynamics of imbibition by soybean embryos. Plant Physiology, v.72, n.1, p.190193, 1983.

VIANA, S.B.A.; FERNANDES, P.D.; GHEYI, H.R.; SOARES, F.A.L.; CARNEIRO, P.T. Índices morfofisiológicos e de produção de alface sob estresse salino. Revista Brasileira de Engenharia Agrícola e Ambiental, v.8, n.1, p.23-30, 2004. 